\title{
Histopathological and Immunohistochemical Analysis of Association between Papillary Carcinoma Thyroid and Hashimoto's Thyroiditis with P63 Immunoprotein
}

\author{
Geetha Lakshmi.S ${ }^{1}$, Martina. $V^{2}$ \\ ${ }^{1,2}$ Assistant Professor, Department Of Pathology, Govtkilpauk Medical College, Chennai, India
}

\begin{abstract}
Neoplastic transformation is a multistep process that results in a continuous spectrum from the physiological state to a fully established neoplasm. Papillary carcinoma thyroid(PTC), the most prevalent of all thyroid carcinomas has been associated with Hashimoto's thyroiditis(HT). Although the gold standard for the diagnosis of PTC is conventional histology,the other criteria being increasingly used include immunohistochemical staining and molecular profile. The aim of this study is to analyse the histopathological types and to establish the association between Hashimoto thyroiditis and papillary carcinoma by immunohistochemical detection of p63 protein. P63 positivity was found in all cases of papillary carcinoma, occasionally in Hashimoto's thyroiditis and absent in Hashimoto thyroiditis with papillary carcinoma. The study showed equivocal results regarding the p63 immunoprotein expression in cases of Hashimoto's thyroiditis with papillary carcinoma. Therefore the association between Hashimoto's thyroiditis and papillary carcinoma remains ambiguous and molecular analysis is required for further confirmation of their association.
\end{abstract}

Keywords: Hashimoto's thyroiditis, papillary carcinoma, p63

\section{Introduction}

Papillary carcinoma of the thyroid is the most common malignant tumor of the thyroid gland, accounting for $80 \%$ of all thyroid cancers. It occurs most commonly in women between $3^{\text {rd }}$ to $5^{\text {th }}$ decades. The interplay between inflammatory and neoplastic disorders, firmly established in certain tissues, is a matter of controversy in the thyroid. An increased risk for developing papillary carcinoma in patients with Hashimoto's thyroiditis remains unproven. A marker found frequently in both of these thyroid disorders is described. Expression of p53 homologous nuclear protein p63 was surveyed in a spectrum of thyroid neoplasms and inflammatory disorders. P63 is postulated to regulate the stem cell phenotype in squamous epithelia, and in tumors of squamous origin.

The expression of p63 protein in Hashimoto's thyroiditis and papillary carcinoma has been studied in this work to establish that they arise from common stem cell precursor. The study herein describes the immunohistochemical detection of p63 in papillary carcinomas of thyroid and Hashimoto's thyroiditis and Hashimoto's thyroiditis with papillary carcinoma tofind out whether p63 expression may constitute a mechanistic pathobiologic link between Hashimoto's thyroiditis and papillary carcinoma thereby indicating identification and appropriate treatment to reduce the incidence of thyroid malignancies.

\section{Material And Methods}

A total of 195 thyroidectomy (hemi sub total and total thyroidectomy) cases received in the Department of pathology, Govtkilpauk medical college from the departments of surgery over a period of 2 years were taken for study. The tissues so obtained were processed and sections were cut at 5 microns. Hematoxylin and eosin staining of the sections were done and various histomorphological changes were studied. Necessary micro photographs were taken. Histopathological diagnosis of the specimens studied included Adenoma, Adenomatous goitre, Nodular goitre, Colloid goitre, Toxic goitre, Multinodulargoitre, Hashimoto's thyroiditis with papillary carcinoma.

Immunohistochemical analysis of p63 was done in 21 cases which included 7 cases of Hashimoto thyroiditis's, 7 cases of papillary carcinoma and 7 cases of Hashimoto's thyroiditis with papillary carcinoma. Cases were selected randomly.P63 nuclear staining pattern and staining intensity was recorded.

\section{Results}

Among the 195 cases studied histomorphologically 137 cases were non-neoplastic lesions(70.26\%) and58 cases were neoplastic $(29.74 \%)$ Table- 1 and further distributed accordingly Table- $2 \& 3$ 
Table-1 Hpe Diagnosis

\begin{tabular}{|l|l|l|}
\hline Thyroid Lesions & No of cases & \% of total \\
\hline Non Neoplastic & 137 & $70.26 \%$ \\
\hline Neoplastic & 58 & $29.24 \%$ \\
\hline
\end{tabular}

Table -2 Distribution Of Non-Neoplastic Thyroid Gland Lesions

\begin{tabular}{|l|l|}
\hline Lesions & No Of Cases \\
\hline Adenomatous Goiter & 33 \\
\hline Multinodular Goiter & 37 \\
\hline Colloid Goiter & 26 \\
\hline Hashimoto's Thyroiditis (Fig1\&2) & 38 \\
\hline Toxic Goiter & 3 \\
\hline Total & 137 \\
\hline
\end{tabular}

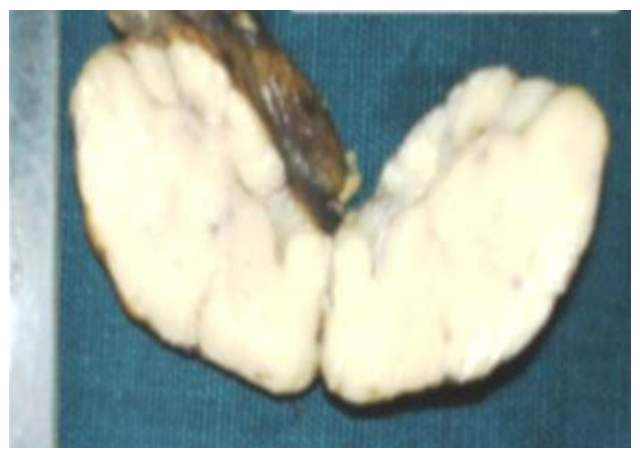

Fig -1 Gross- homogenous and tan

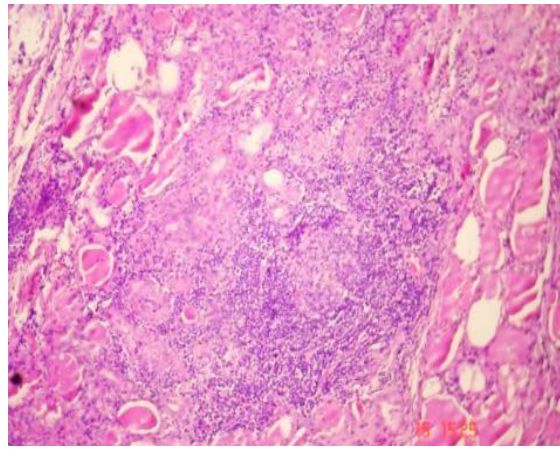

Fig -2 Hashimoto thyroiditis(H\&E)

Table -3 Distribution Of Neoplastic Thyroid Gland Lesions

\begin{tabular}{|l|l|}
\hline Lesions & No Of Cases \\
\hline Follicular Adenoma & 23 \\
\hline $\begin{array}{l}\text { Hashimoto's Thyroiditis With } \\
\text { Papillary Carcinoma(Fig3\&4) }\end{array}$ & 27 \\
\hline Papillary Carcinoma(Fig5\&6) & 7 \\
\hline Medullary Carcinoma & 1 \\
\hline
\end{tabular}

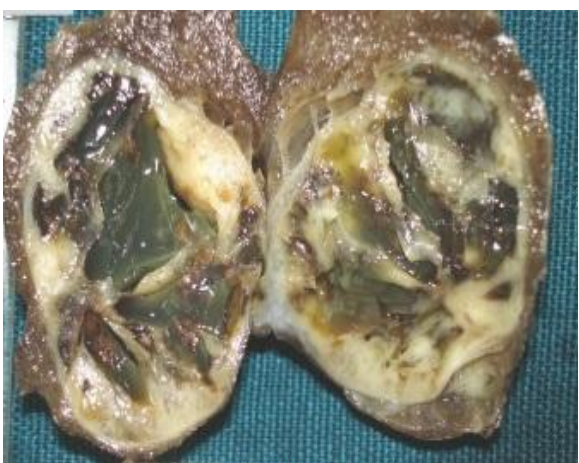

Fig -3 Gross- C/S- grey white with colloid filled and haemorrhagic areas

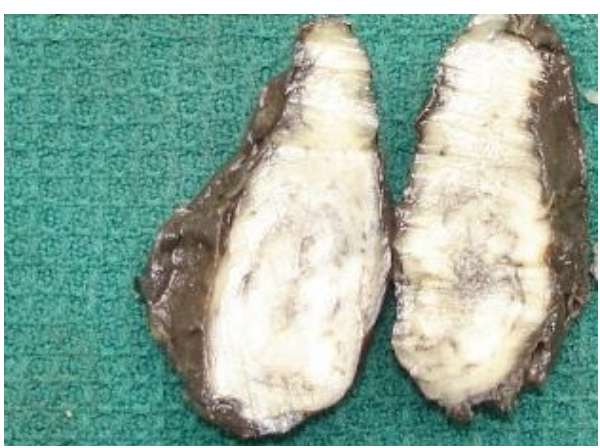

Fig -5 Gross- C/S- grey white with focal haemorrhagic areas

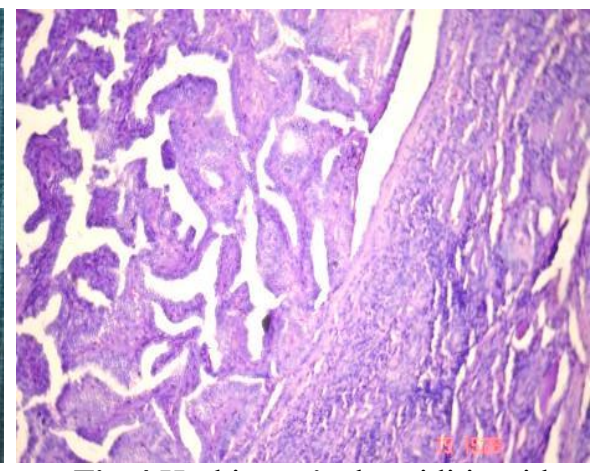

Fig-4 Hashimoto's thyroiditis with papillary carcinoma (H\&E)

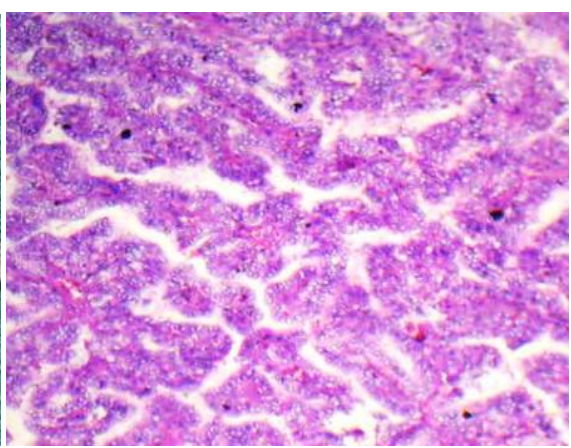

Fig-6 Papillary carcinoma(H\&E)

Www.iosrjournals.org

2 | Page 
Among the 58 neoplastic lesions 23 cases were benign (39.65\%) and 35 were malignant( $60.35 \%)$

Table-4

Table -4 Case Distribution Of Thyroid Neoplasms

\begin{tabular}{|l|l|l|}
\hline Thyroid neoplasms & No of cases & \% of total \\
\hline Benign & 23 & $39.65 \%$ \\
\hline Malignant & 35 & $60.35 \%$ \\
\hline
\end{tabular}

Out of 35 malignant tumors, papillary carcinoma is the commonest histological type accounting for $97.14 \%$ of malignant tumors Table -5

Table-5 Malignant Case Distribution

\begin{tabular}{|l|l|}
\hline Thyroid lesions & No of cases \\
\hline $\begin{array}{l}\text { Hashimoto's thyroiditis with papillary } \\
\text { carcinoma }\end{array}$ & 27 \\
\hline Papillary carcinoma & 7 \\
\hline Medullary carcinoma & 1 \\
\hline
\end{tabular}

Age range was from16 to 75 years. Majority of cases belonged to 30-39 years age group followed by 40-49 years age group.Table-6

Table -6 Age Distribution

\begin{tabular}{|l|l|}
\hline Age & No of cases \\
\hline $10-19$ & 7 \\
\hline $20-29$ & 44 \\
\hline $30-39$ & 69 \\
\hline $40-49$ & 46 \\
\hline $50-59$ & 20 \\
\hline $60-69$ & 6 \\
\hline $70-79$ & 3 \\
\hline TOTAL & 195 \\
\hline
\end{tabular}

Of the 195 cases of thyroid gland lesions 178 cases were female $(91.28 \%)$ and 17 cases were male $8.72 \%)$. Table-7

Table-7 Sex Distribution

\begin{tabular}{|l|l|l|l|l|}
\hline Sex & Non neoplastic & Neoplastic & Total & \% of total \\
\hline Female & 126 & 52 & 178 & $91.28 \%$ \\
\hline Male & 11 & 6 & 17 & $8.72 \%$ \\
\hline
\end{tabular}

P63 immunostain staining intensity was observed and tabulated as follows. Table -8

Table-8 Immunohistochemical Results

\begin{tabular}{|l|l|l|}
\hline HPE diagnosis & No of cases & P63 Immunostain reactivity \\
\hline Papillary carcinoma & 7 & Weak to strong \\
\hline Hashimoto's thyroiditis & 1 & Weak \\
& 6 & Negative \\
\hline Hashimoto's thyroiditis with & 7 & Negative \\
Papillary carcinoma & & \\
\hline
\end{tabular}

The above results show that all isolated cases of papillary carcinoma showed weak to strong positivity of p63 (Fig.7\&8). One case of Hashimoto thyroiditis of showed occasional weak reactivity (Fig.9) and all cases of Hashimoto thyroiditis with papillary carcinoma(Fig.10) and other cases Hashimoto thyroiditis were negative. P63 nuclear staining pattern and staining intensity ranged from strong to moderate to weak. Staining was focal rather than extensive or confluent. Extent of staining varied from multiple positive foci to scattered or rare foci.

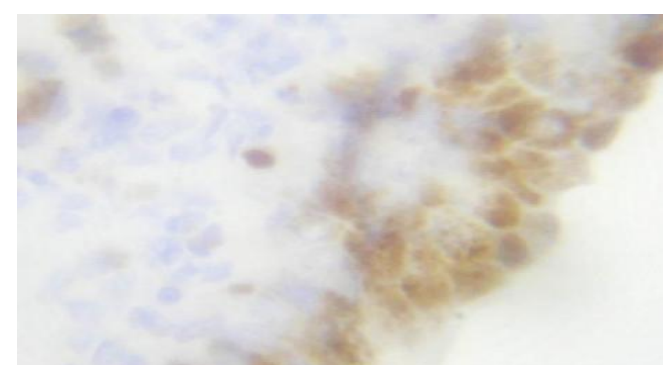

Fig-8 p63 strong diffuse positivity. papillary carcinoma

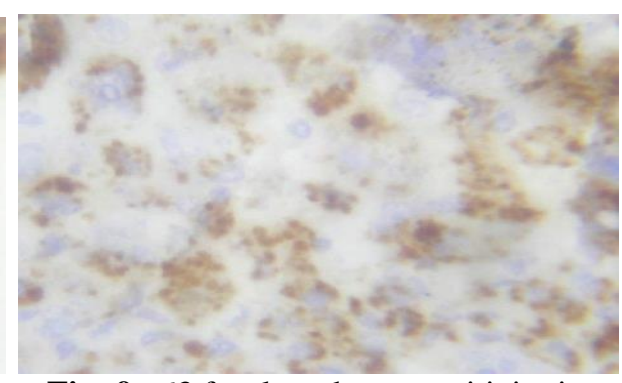

Fig -9 p63 focal moderate positivity in 


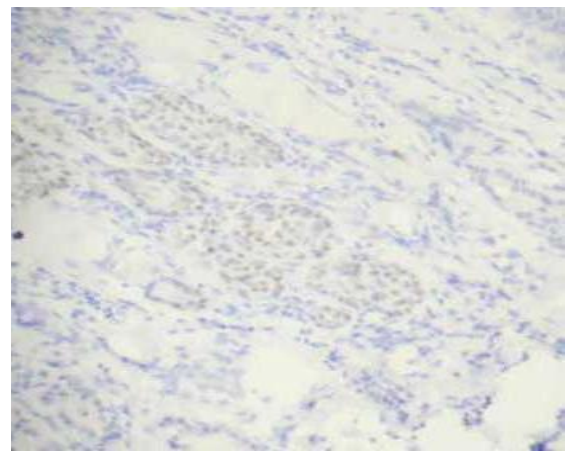

Fig-10 Focal weak positivity in Hashimoto' thyroiditis

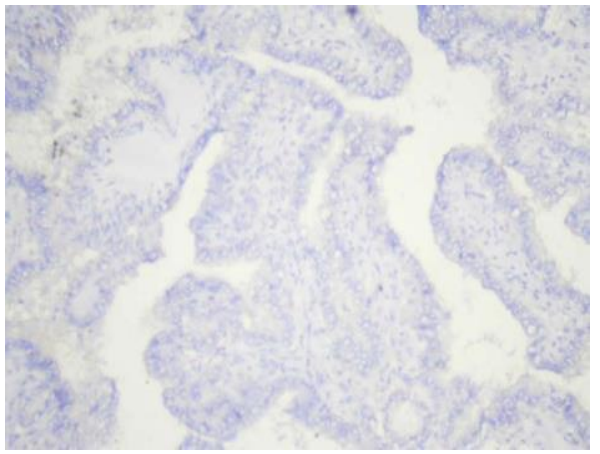

Fig $\mathbf{- 1 1}$ p63 negativity in Hashimoto
thyroiditis with papillary carcinoma

\section{Discussion}

In the present study based on histomorphology non neoplastic lesions outnumbered neoplastic thyroid gland lesions. Among the neoplastic thyroid gland lesions which accounted for $29.74 \%$ of all thyroid lesions papillary carcinoma of thyroid is the most common malignant tumor of the thyroid gland accounting for $97.14 \%$ of malignant tumors $[1,2,3,4]$. In the present study majority of the cases belonged to $3-5^{\text {th }}$ decades $[5,6]$ and twice common in women[7]. The linkage of Hashimoto thyroiditis to papillary thyroid carcinoma is a matter of controversy. The increased risk of developing papillary carcinoma in patients with Hashimoto thyroiditis ranges from $0-30 \%[8,9]$.Among the non neoplastic thyroid gland lesions which accounted for $70.26 \%$ of all thyroid gland lesions Hashimoto's thyroiditis was incidentally found to be more associated with papillary carcinoma than other lesions.[10,11,12]. An attempt was made here to ascertain the possible association between Hashimoto thyroiditis and papillary carcinoma.The possible association between Hashimoto's thyroiditis and papillary carcinoma was studied in cases of Hashimoto thyroiditis, Hashimoto thyroiditis with papillary carcinoma and papillary carcinoma.21 cases were selected randomly which included equal number of cases from each of the above three categories.

P63 immunoprotein status was studied in thesecases.In the current study, p63 was detected in all cases of papillary carcinoma. Staining intensity ranged from weak to strong but distinct. Staining was focal rather than extensive or confluent. Extent of staining varied from multiple positive foci to scattered to rare foci. One case of Hashimoto thyroiditis showed occasional focal p63 staining in follicle like groupings.All cases of Hashimoto thyroiditis with concurrent papillary carcinoma were p63 negative.

The results obtained also correlated with the previous literature results. Table-9[13]

Table-9 Comparative Analysis Of P63 Expression With Previous Studies

\begin{tabular}{|c|c|c|c|c|c|c|}
\hline $\begin{array}{l}\text { Name of } \\
\text { the study }\end{array}$ & $\begin{array}{l}\text { No of cases } \\
\text { of } \\
\text { Hashimoto's } \\
\text { thyroiditis }\end{array}$ & $\begin{array}{l}\text { No of } \\
\text { cases } \\
\text { of } \\
\text { Papillary } \\
\text { carcinoma }\end{array}$ & $\begin{array}{l}\text { No of cases of } \\
\text { Hashimoto's } \\
\text { Thyroiditis } \\
\text { With } \\
\text { Papillary } \\
\text { carcinoma }\end{array}$ & $\begin{array}{l}\text { Hashimoto's } \\
\text { thyroiditis }\end{array}$ & $\begin{array}{l}\text { Papillary } \\
\text { carcinoma }\end{array}$ & $\begin{array}{l}\text { Hashimoto's } \\
\text { With } \\
\text { papillary } \\
\text { carcinoma }\end{array}$ \\
\hline $\begin{array}{l}\text { Pamelaunger } \\
\text { et.al } \\
2003 \\
\end{array}$ & 13 & 33 & 17 & $9 / 13$ & $27 / 33$ & $\begin{array}{l}15 / 17 \\
(88.2 \%)\end{array}$ \\
\hline $\begin{array}{l}\text { Jorge S et.al } \\
\text { Modern } \\
\text { pathology } \\
2003 \\
\end{array}$ & - & 6 & - & - & $\begin{array}{l}6 / 6 \\
(100)\end{array}$ & - \\
\hline $\begin{array}{l}\text { Dina BL } \\
\text { Demellawy } \\
\text { et.al.diagnostic } \\
\text { pathology }\end{array}$ & - & 75 & - & - & $\begin{array}{l}52 / 75 \\
(70 \%)\end{array}$ & - \\
\hline Present study & 38 & 27 & 7 & $\begin{array}{l}1 / 38 \\
(0.026 \%)\end{array}$ & $\begin{array}{l}27 / 27 \\
(100 \%)\end{array}$ & - \\
\hline
\end{tabular}

These studies have also shown equivocal results regarding the p63 immunoprotein expression in cases of Hashimoto's thyroiditis with papillary carcinoma. Therefore the association between Hashimoto's thyroiditis and papillary carcinoma remains ambiguous. The theory of common precursor stem cell origin of Hashimoto's thyroiditis and papillary carcinoma could not be confirmed. Thus p63 positivity, although common to papillary carcinoma,Hashimoto thyroiditis and thyroid cells with squamoid features, a mechanistic role in linking these various entities cannot be proved because of the following reasons.[13] 
- Failure to explain the existence of p63 positive papillary carcinomas that occur in the absence of Hashimoto's thyroiditis.

- Failure to account for p63 negative cases of Hashimoto's thyroiditis.

- Failure of expression of p63 in all cases of Hashimoto's thyroiditis with concurrent papillary carcinoma.

Therefore the theory of common precursor stem cell origin of Hashimoto's thyroiditis and papillary carcinoma could not be confirmed in this study and molecular analysis is needed for definite confirmation.[14,15]

\section{CONCLUSION}

The possible association between Hashimoto thyroiditis and papillary carcinoma could not be established because of occurrence of p63 negative cases of Hashimoto thyroiditis and lack of expression of p63 in all cases of Hashimoto's thyroiditis with concurrent papillary carcinoma.Therefore molecular analysis is required for further confirmation of their association.

\section{References}

[1]. De Lellis R.A., Williams ED 2004 Thyroid and parathyroidtumors. Introduction. In: De Lelis RA, Llyoid RV, Heitz P U et al(eds) Pathology and genetics. Tumors of endocrine oxaus. World Health Organisation classification of tumors.IARC Lyon P. 49-56. .

[2]. Rosai J. Carcangui ML, De bllins RA, Tumors of the thyroid gland InJosai J, Sobin LE. Atlas of tumor pathology Vol.5, $3^{\text {rd }}$ Series Fascicle.5, Washington, DC, Armed Forces Institute of Pathology, 1992.

[3]. Gilliland FD, Hunt WC, Morris DM et al, 1997 Prognostic factors for thyroid carcinoma. A population based study of 15, 698 cases from the surveillance, Epidemiology and end results (SEER)program 193-1991, Cancer 79: $564-573$

[4]. Schlumberger MJ 1998, Papillary and follicular thyroid CarcinomaN. Engl J Med 338: $297-306$.

[5]. McConahey W, et al Papillary thyroid cancer treated at the mayo clinic, 1946 through 1970: initial manifestation pathologic findings, therapy and outcome Mayo clicProc 1986; 61: 978-996.

[6]. Mazzaferi EL, Young RL, Papillary thyroid carcinoma; a $10 \mathrm{yr}$ follow up report of the impact of therapy in 576 patients. Am J med 1981; 70-511-518.

[7]. Carcangui ML, Zampig.Pupi A, et al, Papillary carcinoma of thyroid; a clinico - pathologic study of 241 cases treated at the university of florence, Italy, Cancer $1985 ; 55: 805-828$

[8]. Arif SI, Blanas A ,Diaz-canos. hashimotos thyroiditis shares features with early papillary carcinoma.histopathology 2002 oct;41(4):357-62

[9]. Anand A, singh,kushwahajk, hussain,sonkar. papillary carcinoma andhashimoto's thyroiditis: An association less understood. Indian J surg oncol.2014 sep;5(3):199-204

[10]. Daniel repplinger,B.S;AnnaBargren, B.S,Yi Zhang. Is hashimoto's thyroiditis a risk factor for papillary thyroid cancer.?JSurg.Res. 2008 Nov;150(1):49-52

[11]. Cippola c, sandonato L, Fricanos,Torcinia,venis. Hashimoto's thyroiditis co-existent with papillary thyroid carcinoma.Am.Sugr. 2005; 71:874-878

[12]. Huang BY, Hseuh c, ChanoTc, Link JD. Well differentiated carcinoma with concomitant hashimoto's thyroiditis present with less aggressive clinical stage and low recurrence.Endocr path 2011 Sep;22(3):144-9 .

[13]. Pamela unger ,M.D.MichellaEwast,M.DBerelyy,Wang M.D. Expression of p63 in papillary throid carcinoma and in hashimoto's thyroiditis; A Pathologic link. Human pathology volume 24, No :8 August 2003

[14]. Bongarzone I Bulli MG, Coronelli S, Borrello MG, Santoro M, Mondellini P, Pilloti S, Fusco A, Della Porta G, Pierotti MA (1994). Frequent activation of ret proto oncogene by fusion with a new activating gene in papillary thyroid carcinomas ,Cancer Res 54; $2979-2985$.

[15]. Santoro M, Dathan NA, Berlingieri MT, Bongarzore I, Paulin C, Grieco M, Pierotti MA, Vacchio G, Fusco A (1994). Molecular characterization of RET/PTc3; a novel rearranged version of the RET proto oncogene in human thyroid papillary carcinomaoncogene 9: 509-516. 